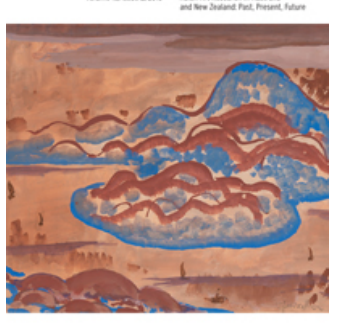

ISSN: 1443-4318 (Print) 2203-1871 (Online) Journal homepage: https://www.tandfonline.com/loi/raja20

\title{
Anachronistic Histories: Eugenia Lim's Yellow Peril
}

Bus Projects, Melbourne, 8-25 April 2015

\section{Kate Warren}

To cite this article: Kate Warren (2016) Anachronistic Histories: Eugenia Lim's Yellow Peril, Australian and New Zealand Journal of Art, 16:2, 264-267, DOI: 10.1080/14434318.2016.1239515

To link to this article: https://doi.org/10.1080/14434318.2016.1239515

曲 Published online: 10 Nov 2016.

Submit your article to this journal $₫$

山 Article views: 58

Q View related articles ¿

View Crossmark data $₫$ 


\title{
REVIEW
}

\author{
Anachronistic Histories: Eugenia Lim's Yellow Peril, Bus Projects, \\ Melbourne, 8-25 April 2015
}

One of the most compelling qualities of Melbourne artist Eugenia Lim's Yellow Peril is its multi-layeredness. Lim's aesthetically precise, conceptually rich project explores complex histories and connections across time, space, and cultures. A multi-part exhibition including video, sculpture, and photographic prints, Yellow Peril interweaves colonial, personal, and contemporary histories. Visiting the exhibition is rather like travelling through time-except it is unclear whether you're travelling into the past, the future, or perhaps an alternate present. Embodied in Lim's performative persona, this anachronistic quality becomes a tool for exploring myriad cross-cultural and multi-temporal links across historical and contemporary Australian-Chinese relations.

Two photographic images dominate Lim's exhibition, both printed large-scale on gold mylar emergency blankets (fig. 1). One is of her parents in 1980, standing in front of Ron Robertson-Swann's often-maligned public sculpture Vault (1978)—commonly known by its pejorative nickname, the 'Yellow Peril'. This photograph was a key catalyst for Lim's project. The second image is a souvenir portrait that Lim had taken at Victoria's popular tourist attraction, Sovereign Hill, a recreation of Ballarat during the mid-nineteenth century 'gold rush'. Lim poses amongst the staged period setting, holding a large replica gold nugget. These two images encapsulate the levels of history, memory, cultural symbolism, and national mythologies at play in the exhibition.

The persona that Lim adopts in her portrait references Hong Kong-born artist Tseng Kwong Chi (1950-1990). In the late 1970s and 1980s Tseng made a series of selfportraits, posing in front of iconic tourist locations. Dressed as an 'ambiguous ambassador', in sunglasses and classic Mao suit, Tseng's humorous and critical photographs rely on a sense of him being out-of-place and out-of-time. ${ }^{1}$ Donald M. Lowe links Tseng's images to a sense of fragmented identity, reflecting 'life constructed by the deterritorialization, detemporalization, and decoding/recoding of late capital'. ${ }^{2}$ Moreover, Tseng's Mao suit costume feels politically out-of-time, a sardonic nod to the post-Mao era presided over by the then newly anointed preeminent leader Deng Xiaoping.

This same multifaceted quality of anachronism pervades Lim's entire project. In her video performance, Lim adopts a similar persona to Tseng, wandering through Sovereign Hill in a bright gold Mao suit. Yellow Peril expands the connection between anachronism and personal identity to incorporate historically complex temporalities. Anachronism is an important concept in contemporary art and historical studies. 


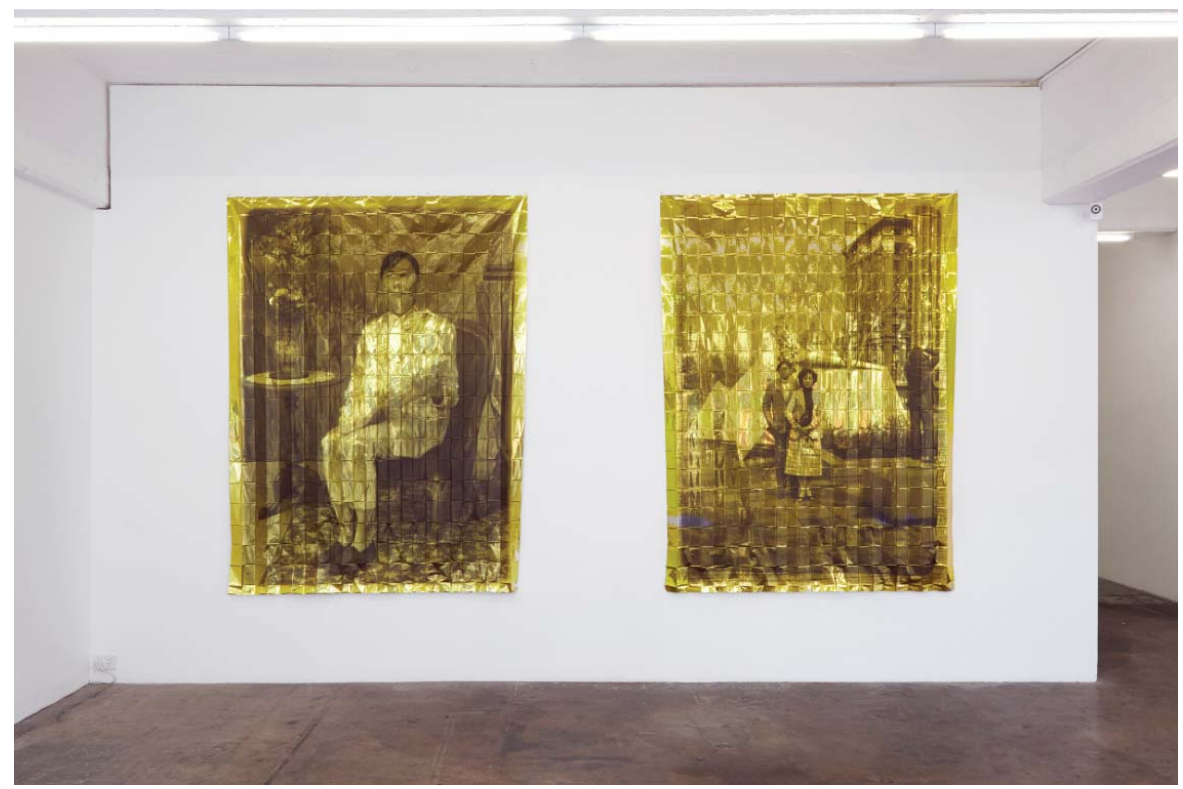

Figure 1. Eugenia Lim, Yellow Peril, 2015. Installation documentation, Bus Projects, Melbourne, 2015. Photo credit: Zan Wimberley.

Numerous art theorists have adopted themes of anachronism and 'untimeliness' as ways of theorising what it means to be 'contemporary'. ${ }^{3}$ In historical disciplines, however, anachronism has been considered the biggest 'sin' a historian can make, by erroneously imposing present assumptions on the past. ${ }^{4}$ In light of such tensions, artists who work with historical subjects could be considered permanently entangled in competing temporalities.

Yellow Peril developed out of Lim's research into how Australia's development as a colonial nation-state was connected to immigration, mining, and the exclusion of racial and social groups. It does not take much delving to realise that Australia's historical connections with Asia are themselves anachronistic and full of exceptions. The myth of terra nullius constructed the idea of an uninhabited land, denying the cross-cultural and economic connections that already existed between Aboriginal and Torres Strait Islander people and their Asian neighbours. ${ }^{5}$ The supposed 'birth' of Australian democracy-the 1854 Eureka Rebellion-was largely at the expense of commensurate rights for Chinese (and other) workers on the goldfields, and the Immigration Restriction Act 1901 overtly delineated the newly federated nation from its Asian neighbours. However, such social and political boundaries were, to varying extents, porous. Japanese labour was so important to northern Western Australia's turn-of-the-century pearling industry, for instance, that it was exempted from the Act. ${ }^{6}$ While not officially repealed until 1973, the Act's restrictions were progressively 
relaxed over the preceding decades, including through the Colombo Plan-in which Lim's father, a general practitioner, participated in the 1960s. ${ }^{7}$

Such personal connections are entwined with broader social histories in Yellow Peril. Seen today, the photograph of Lim's parents assumes an ironic but also humorously poignant quality. For Lim, Robertson-Swann's sculpture mirrors Chinese history in Australia. Much maligned in its day, Vault is now celebrated as an icon within Melbourne's visual culture. Yet, through its commonly used moniker, it also represents lingering stereotypes and anxieties about Asian immigration. The 'Yellow Peril' is a site where layers of history unwittingly resurface. Lim's project draws out connections that permeate across eras and contexts, and in doing so she reminds viewers of the contradictions within history and memory that stubbornly persist, perhaps never to be resolved.

In a similar vein to Vault's enduring nickname, almost anyone who grew up in Victoria will have visited Sovereign Hill, making it a site of mixed histories and blurred memories. A 'living history' reconstruction of Victoria's goldfields, Sovereign Hill embodies the slippages between past and present that Lim effortlessly exploits. On first viewing her video, I thought that Lim's actions, panning for gold in a shining golden suit, must have seemed highly irregular to those around her-an incongruous presence, both nostalgic and futuristic. But later, it struck me that Sovereign Hill's utterly constructed façade-where everyone is costumed, to some extent-in fact allows Lim to fade-in and fade-out of her surroundings with surprising ease.

This is evident in the video's early wide-shot of the main street, as Lim's deadpan figure emerges unassumingly from the distance. Unmissable yet unobtrusive, Lim embodies the interplays between historical presence and absence that characterise sites like Sovereign Hill. In doing so, she draws attention to the unevenness with which Australia's history has acknowledged marginalised stories that don't fit neatly into a dominant, linear narrative (like those of Chinese labourers, or dispossessed Indigenous people). Since its opening in 1970, Sovereign Hill's recognition of diverse histories has improved; however, Lim acknowledges that this remains somewhat tokenistic. ${ }^{8}$ The enduring popularity of Sovereign Hill as a destination for school groups reinforces the ongoing influence that such attractions have in maintaining national myths. Yet for all its kitsch historicism, Sovereign Hill offers a fascinating snapshot of contemporary Australian-Chinese relations: Chinese and Asian tourists feature prominently in Lim's video, subtly reflecting the shifting cultural and geopolitical relations that continue to define and challenge contemporary Australia.

With Yellow Peril, Lim seduces and provokes. Her exhibition's confronting title also reflects her broader love of wordplay, especially the ways that meaning migrates through language and pre-existing cultural frameworks. Thus Lim does not overtly 'critique' Sovereign Hill's living history construct; she mimics it. She engagingly pulls her viewers into a precisely constructed world, but one that is nuanced, unsettled, contradictory and complementary. Lim's critically provoking yet aesthetically seductive approach to cross-cultural histories connects with the work of a number of other contemporary artists, including Shoufay Derz's recent exploration of mining and landscape, The Wish (2015), Danie Mellor's multi-media cultural assemblages, or 
Jason Wing's cross-cultural examinations of hidden histories. For Lim, Yellow Peril is an ongoing project, its future iterations in Sydney and Seoul attesting to the exhibition's sense of unfinished histories and fluid cultural connections.

\author{
Kate Warren \\ Monash University \\ kate.warren@monash.edu \\ (c) 2016, Kate Warren
}

1. Tseng Kwong Chi, Ambiguous Ambassador (Tucson: Nazraeli Press, 2005)

2. Donald M. Lowe, 'Against Nostalgia: The Photo Image of Tseng Kwong Chi', Positions: Asia Critique 2, no. 2 (1994): 412.

3. Including Jacques Rancière, Giorgio Agamben, Peter Osborne, and Boris Groys.

\author{
4. Margreta De Grazia, 'Anachronism', in Cultural \\ Reformations, eds James Simpson and Brian Cum- \\ mings (Oxford: Oxford University Press, 2010), 13. \\ 5. Regina Ganter, Mixed Relations (Crawley: Univer- \\ sity of Western Australia Press, 2006). \\ 6. Ibid., 66. \\ 7. Eugenia Lim, email to author, 24 June 2016. \\ 8. Discussion with the artist, 31 May 2016.
}

